\title{
Skull Base Angle Morphometry in South Indian Population with Review on Terminology
}

\author{
Veeramani Raveendranath ${ }^{1} \quad$ Prafulla Kumar Dash ${ }^{2} \quad$ Krishnan Nagarajan ${ }^{3, \odot}$ Thangaraj Kavitha ${ }^{1}$ \\ Srinidhi Swathi ${ }^{1}$
}

${ }^{1}$ Department of Anatomy, Jawaharlal Institute of Postgraduate

Medical Education \& Research, Puducherry, India

${ }^{2}$ Department of Radiodiagnosis, Kalinga Institute of Medical Sciences, Bhubaneswar, Odisha, India

${ }^{3}$ Department of Radiodiagnosis, Jawaharlal Institute of

Postgraduate Medical Education \& Research, Puducherry, India

\begin{abstract}
Address for correspondence Krishnan Nagarajan, MD, DM, Department of Radiodiagnosis, Jawaharlal Institute of Postgraduate Medical Education \& Research (JIPMER), Dhanvantri Nagar, Puducherry 605006, India (e-mail: Iknagarajan1@gmail.com).
\end{abstract}

Indian J Neurosurg 2022;11:136-139

\begin{abstract}
Introduction Basal angle, Boogaard's angle, and clival angle are frequently used in diagnosing the craniometric angle malformations either on radiography or now more on MRI. But anatomic and clinical studies have used varied terms for these parameters. We aimed to look for these parameters among a normal south Indian adult population to standardize the measurements and their terminology.

Materials and Methods One hundred MRI images ( 50 males and 50 female) were studied retrospectively. MRI images that were reported as normal by neuroradiologist were taken up for the study. Mean and the standard deviation of males and females were calculated for basal angle, Boogaard's angle, and clival angle, separately. Unpaired $t$-test was used to analyze the significant difference $(p<0.05)$ between the genders. The intraclass coefficient correlation was used to analyze the interobserver variability. Results The mean value of basal angle in males and females are $113^{\circ}$ and $114^{\circ}$, respectively. The mean value of Boogaard's angle in males and females are $120^{\circ}$ and $121^{\circ}$, respectively. The mean value of clival angle in males and females are $157^{\circ}$ and

Keywords

- basal angle

- Boogaard's angle

- clivus-canal angle

- magnetic resonance imaging

- terminology

$155^{\circ}$, respectively. There was no statistically significant difference $(p>0.05)$ between males and females in all three angles.

Conclusion Knowledge about the normal angles will be an important tool in understanding the normal and abnormal skull base. Since the type of skull varies in accordance with race, the normal craniometric angle also varies in accordance with race. The present study tried to standardize the parameters of normal skull base angles for appropriate correction of the anomalies and uniform usage of terminology.
\end{abstract}

\section{Introduction}

The atlas, axis, and the occiput bone form the craniovertebral junctions. Craniometric angles are angles formed between the posterior skull base and the cervical spine. Basal angle, Boogaard's angle, and clival angle are frequently used in diagnosing the craniometric angle malformations, based on radiography/cephalogram or now more on MRI. Chiari malformation

published online May 13, 2021
DOI https://doi.org/

$10.1055 / \mathrm{s}-0041-1722824$ ISSN 2277-954X. and basilar invagination are two major clinical conditions due to the craniovertebral junction (CVJ) malformation. Platybasia and hyperlordosis are often associated with basilar invagination..$^{1-3}$ Since the anatomical bony landmarks required for the angle measurements are easily accessible, it can be used as a standard diagnostic tool in CVJ malformations. In the literatures, few studies have mentioned the normal range of angles based on comparative studies. Additionally, few factors like race, sex, age,

(c) 2021. Neurological Surgeons' Society of India.

This is an open access article published by Thieme under the terms of the Creative Commons Attribution-NonDerivative-NonCommercial-License, permitting copying and reproduction so long as the original work is given appropriate credit. Contents may not be used for commercial purposes, or adapted, remixed, transformed or built upon. (https://creativecommons.org/licenses/by-nc-nd/4.0/).

Thieme Medical and Scientific Publishers Pvt. Ltd. A-12, 2nd Floor, Sector 2, Noida-201301 UP, India 
and height of an individual can alters the CVJ craniometry. ${ }^{4,5}$ To the best of our knowledge, no study has been conducted to evaluate the normal craniovertebral angles among the south Indian population. Since the MRI is an emerging gold standard and low-radiation exposure investigation in diagnosing the soft-tissue pathologies, the aim of the study is to define the normal range of basal angle, Boogaard's angle, and clival angle for men and women among the south Indian population based on MRI.

\section{Materials and Methods}

One hundred MRI images (50 males and 50 female) were studied retrospectively. MRI images taken for other clinical conditions like seizure disorders and headache, reported as normal by neuroradiologist, were taken up for the study. The images were retrieved from the picture archiving and communication system (PACS) after obtaining approval from the institute research monitoring and ethical committee (IEC). MRI images were taken in 1.5 Tesla MR equipment (Magnetom Avanto Siemens, Erlangen Germany) using a 14-channel head coil. High-resolution, heavily T2-weighted 3D sequence sampling perfection with application optimized contrasts using different flip-angle evolution (SPACE) was used to acquire thin $1 \mathrm{~mm}$ sections. The scanning parameters were TR/ TE-1200/162 milliseconds; section thickness $1 \mathrm{~mm}$; no. of sections-120; FOV 220 mm; flip angle $150^{\circ}$; matrix $192 \times 256$. Thin section T1-weighted magnetization prepared rapid gradient echo (MPRAGE) sequence was also acquired with similar parameters for comparison. The direct sagittal plane was used for better in-plane resolution. True sagittal sections were ensured by the presence of stalk, infundibular recess, cerebral aqueduct, and anterior-posterior commissural line in the same visualized midsagittal plane image.

The following measurements were taken in sagittal view:

(a) Basal angle-angle between the line extending from nasion

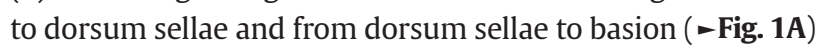

(b) Boogaard's angle-angle between the line extending from dorsum sellae to basion and from basion to opisthion ( - Fig. 1B) (c) Clival angle-angle between the line extending from dorsum sellae to basion and line along the posteroinferior surface dens (-Fig. 1C)
All the information was collected in a deidentified way. The data was measured thrice, and the average was taken as final. The same was measured by the second observer to determine the interobserver variability. Mean and the standard deviation of males and females was calculated for basal angle, Boogaard's angle, and clival angle, separately. Unpaired $t$-test was used to analyze the significant difference $(p<0.05)$ between the genders. The intraclass coefficient correlation was used to analyze the interobserver variability.

\section{Results}

- Table 1 shows the mean values of all the parameters. Fig. 2 shows the graphical representation of the parameters. The mean value of basal angle in males and females are $113^{\circ}$ and $114^{\circ}$, respectively. The mean value of Boogaard's angle in males and females are $120^{\circ}$ and $121^{\circ}$, respectively. The mean value of clival angle in males and females are $157^{\circ}$ and $155^{\circ}$, respectively. There was no statistically significant difference $(\mathrm{p}>0.05)$ between males and females in all three angles. The interobserver correlation coefficients for the basal, Boogard's and clival angle were $0.70,0.78$ and 0.80 , respectively.

\section{Discussion}

CVJ angular geometry formed by the skull base and the cervical vertebra can be determined by craniometric angles like basal angle, Boogaard's angle, and clivus-canal angle. ${ }^{2}$ Anterior skull base and the clivus influences the basal angle and the Boogaard's angle, respectively. Basal angle is formed by the line extending from nasion to dorsum sellae and from dorsum sellae to basion. The mean basal angle was $113^{\circ}$ (males $113^{\circ} \pm$ $5^{\circ}$ and females $114^{\circ} \pm 4^{\circ}$ ). There was no statistically significant difference between males and females. The present study correlates well with the MRI study conducted by Botelho and Ferreira, Koenigsberg et al and Hirunpat et al. ${ }^{1,2,4}$ Boogaard's angle is formed by the line extending from dorsum sellae to basion and from basion to opisthion. The mean Boogaard's angle was $120^{\circ}$ (males $120^{\circ} \pm 10^{\circ}$ and females $121^{\circ} \pm 5^{\circ}$ ). There was no statistically significant difference between males and
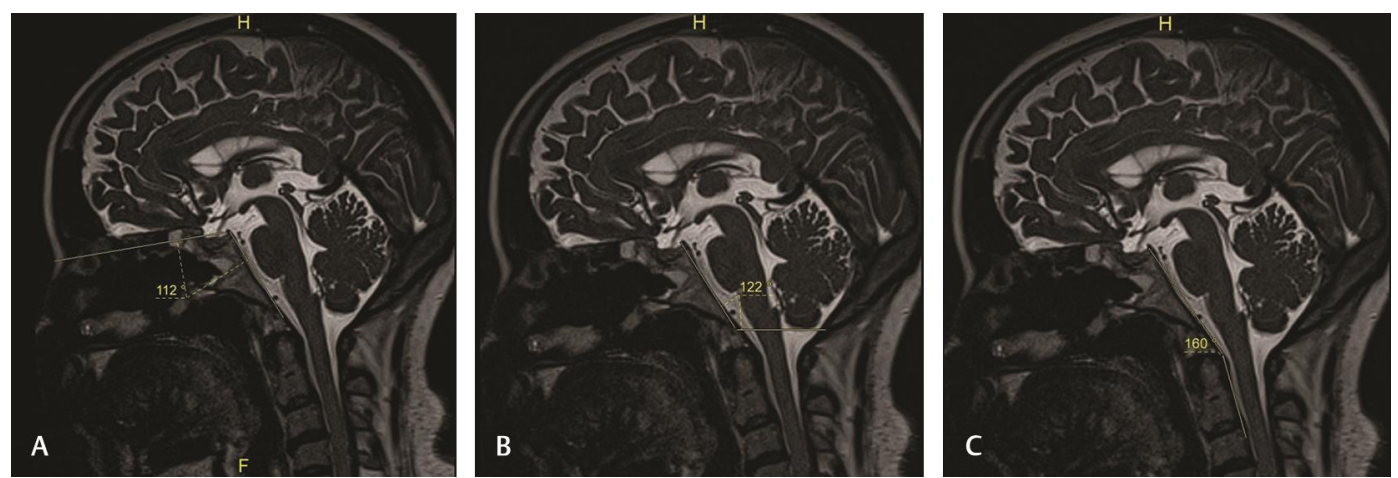

Fig. 1 Sagittal heavily T2-weighted 3D sampling perfection with application optimized contrasts using different flip-angle evolution (SPACE) MRI images of brain in midsagittal plane showing the basal angle (A), Boogaard's angle (B) and the clivus-canal angle (C). 
Table 1 Showing the measurements of skull base angles in normal adult males (50) and females (50)

\begin{tabular}{|l|l|l|l|l|l|l|}
\hline Angle & $\begin{array}{l}\text { Mean } \\
(\mathbf{1 0 0})\end{array}$ & $\begin{array}{l}\text { Male } \\
(\text { mean } \pm \text { SD) }\end{array}$ & Range & $\begin{array}{l}\text { Female } \\
(\text { mean } \pm \text { SD) }\end{array}$ & Range & Significance \\
\hline Basal angle & 113 & $113^{\circ} \pm 5^{\circ}$ & $111^{\circ}-114^{\circ}$ & $114^{\circ} \pm 4^{\circ}$ & $113^{\circ}-116^{\circ}$ & $p=0.13$ \\
\hline Boogaard's angle & 120 & $120^{\circ} \pm 10^{\circ}$ & $118^{\circ}-123^{\circ}$ & $121^{\circ} \pm 5^{\circ}$ & $119^{\circ}-123^{\circ}$ & $p=0.68$ \\
\hline Clivus-canal angle & 156 & $157^{\circ} \pm 9^{\circ}$ & $154^{\circ}-159^{\circ}$ & $155^{\circ} \pm 7^{\circ}$ & $153^{\circ}-158^{\circ}$ & $p=0.41$ \\
\hline
\end{tabular}

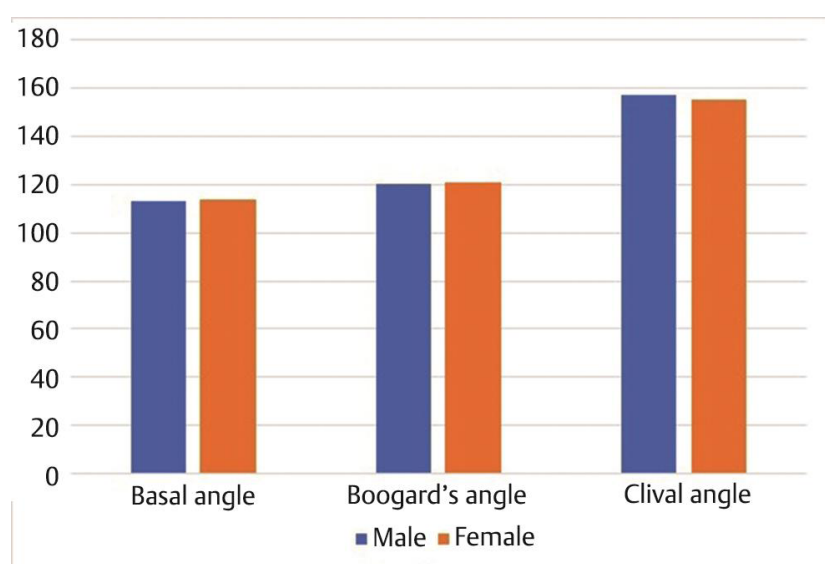

Fig. 2 Graphical representation of craniometric angles in males and females.

females. Botelho et al in a previous study in Brazilian population found Boogaard's angle to have a slightly greater mean value of $126 .{ }^{2}$ Clival angle is formed by the line extending from dorsum sellae to basion and from posteroinferior surface of axis to posterosuperior surface of dens. The mean measurement was $156^{\circ}\left(\right.$ males $157^{\circ} \pm 9^{\circ}$ females $155^{\circ} \pm 7^{\circ}$ ). There was no statistically significant difference between males and females. This measurement was slightly more than the study conducted by Botelho and Ferreira (mean $148^{\circ}$ ) and Smoker (mean $\left.150^{\circ}\right) .^{2,6}$

CVJ malformation can be of congenital or acquired condition. Few congenital conditions of craniofacial anomalies are osteogenesis imperfecta, craniocleidodysostosis, ArnoldChiari malformation, basilar invagination (type I and type II), and platybasia. Abnormal skull base flattening or basal angle enlargement was defined as platybasia. ${ }^{1,2}$ It can be of isolated condition or associated with other conditions. The isolated condition is mostly asymptomatic. Platybasia associated with basilar invagination (type II) shows signs of upper cervical spinal cord and brainstem compression. Some acquired conditions like Paget disease, osteomalacia, rickets, hyperparathyroidism, localized bone destruction, and trauma can also be associated with CVJ deformation. ${ }^{1,4}$ Basal angle and Boogaard's angle are considered as primary angle, because these angles are not altered by craniocervical posture and balance. The clival angle is considered as secondary angle in evaluating the craniocervical junction malformation. In platybasia, clival angle was more acute and the Boogaard's angle was wide. Along with this, the basal angle was also wide in basilar invagination. ${ }^{2}$ Frade et $\mathrm{al}^{7}$ measured these craniovertebral transition parameters in normal Brazilian population and found that basal angle was $128.96^{\circ}$ mean (SD 6.51) and the clivus canal angle was $150.5^{\circ}$ mean (interquartile range
[IQR] 143.2-157.3). Xu and Gong ${ }^{8}$ proposed clivus-dens angle as measures in sagittal CT reformation as an alternative to clivus-canal angle with a better diagnostic performance. Kovero et $\mathrm{al}^{9}$ studied cephalometric evaluation of various measurements in 54 patients with osteogenesis imperfecta and normal volunteers including the basal angle (anterior cranial base angle) and cranio-vertebral angle (measured between nasion-sella line and longitudinal axis of odontoid process of C2). The basal angle showed significant difference between normal and those with platybasia due to osteogenesis imperfecta, and the angle was larger in more severe type of OI than type I. In a study of skull base angle morphometry of patients with Apert syndrome, Lu et $\mathrm{al}^{10}$ did not find any significant changes in basal angle.

Skull base development is now considered a related determinant for facial growth or jaw/maxillomandibular occlusal schemes, and basal angle changes have been studied in those with dental/skeletal malocclusion. ${ }^{11}$ It has been reported that the basal angle is larger or normal in class II malocclusion and smaller or normal in class III malocclusion. ${ }^{12}$ But Guyot et $\mathrm{al}^{12}$ called the basal angle between the sphenoethmoidal plane and clival plane as clival angle as described by Landzert first in 1866.

The basal angle had also been correlated with other measurements to quantify the small posterior fossa seen in Chiari malformations. ${ }^{13,14}$ The basal angle and Boogaard's angle were wider in 22 patients with Chiari malformation even though platybasia was noted only in three patients. Hwang in their report of 12 patients with Chiari malformation described the Boogaard's angle and angle of the clivus and showed that this angle and the angle between the supraoccipital and McRae's line were significantly larger in Chiari group, indicating the steep clivus of narrow posterior fossa.

The basal angle is the most commonly used angle in diagnosing the platybasia and is considered as primary angle. - Table 2 shows the comparison of angles with the previous studies. Knowledge about the normal angle will be an important tool in planning the treatment involving the skull base. Since there may be racial differences in the type of skull, the normal craniometric angles also vary according to the race. The present study is an attempt to look for the parameter of skull base angles in the normal population, so that it can be used as a standard tool in the appropriate method of correction of the anomalies. However, the sensitivity of the normal value is to be evaluated clinically for the south Indian populations.

There is confusion in the usage of the terminology with basal angle mentioned as anterior cranial base angle, Welcher basal angle, and even as clival angle. Similarly, the 
Table 2 Showing the comparison of skull base angles with previous studies

\begin{tabular}{|c|c|c|c|c|c|}
\hline S. No & Author & Study & Basal angle & Clival angle & Boogard's angle \\
\hline 1. & Batista et $a^{5}$ & CT & 113.7 & 153.6 & - \\
\hline 2. & Botelho et al ${ }^{2}$ & MRI & 119 & 148 & 126 \\
\hline 3. & Koenigsberg et al ${ }^{1}$ & MRI & 117 & - & - \\
\hline 4. & Hirunpat et a $\left.\right|^{4}$ & MRI & 117 & - & - \\
\hline 5. & Smoker ${ }^{6}$ & MRI & 132 & 150 & - \\
\hline 6. & Xu and Gong ${ }^{8}$ & $\mathrm{CT}$ & & $149.6 \pm 8.7$ & \\
\hline 7. & Hwang et al ${ }^{14}$ & MRI & & & 117.42 \\
\hline 8. & Kovero $^{9}$ & Cephalogram & 129.8 & & \\
\hline 9. & Guyot et al ${ }^{12}$ & Skull & $124.14 \pm 10.04$ & & \\
\hline 10. & Karagoz et al ${ }^{13}$ & MRI & $121 \pm 6$ & & $137 \pm 6^{*}$ \\
\hline 11. & Frade et al ${ }^{7}$ & MRI & $128.96( \pm 6.51)$ & $150.14(+15.37)$ & \\
\hline 12. & Present study & MRI & 113 & 156 & 120 \\
\hline
\end{tabular}

Boogaard's angle is described as angle of the clivus in some studies. There is need for uniformity and standardization of the terminology among the clinicians of radiology, neurosurgery and orthopedics apart from the anatomists for better research data management, which is now widely available due to routine neuroimaging using CT or MRI.

Conflict of Interest

None declared.

\section{References}

1 Koenigsberg RA, Vakil N, Hong TA, et al. Evaluation of platybasia with MR imaging. Am J Neuroradiol 2005;26(1):89-92

2 Botelho RV, Ferreira ED. Angular craniometry in craniocervical junction malformation. Neurosurg Rev 2013;36(4):603-610

3 Botelho RV, Diniz JM. Basilar Invagination: cranio-cervical kyphosis rather than prolapse from the upper cervical spine. J Neurol Neuromed 2017;2:15-19

4 Hirunpat S, Wimolsiri N, Sanghan N. Normal value of skull base angle using the modified magnetic resonance imaging technique in Thai population. J Oral Health Craniofac Sci 2017;2:17-21

5 Batista UC, Joaquim AF, Fernandes YB, Mathias RN, Ghizoni E, Tedeschi $\mathrm{H}$. Computed tomography evaluation of the normal craniocervical junction craniometry in 100 asymptomatic patients. Neurosurg Focus 2015;38(4):E5

6 SmokerWR. Craniovertebral junction: normal anatomy, craniometry, and congenital anomalies. Radiographics 1994;14(2):255-277
7 Frade HC, França CC, Nascimento JJ, Holanda MM, Silva EJD, Araújo SA. Cranio-vertebral transition assessment by magnetic resonance imaging in a sample of a northeast Brazilian population. Arq Neuropsiquiatr 2017;75(7):419-423

$8 \mathrm{Xu} \mathrm{S}$, Gong R. Clivodens angle: a new diagnostic method for basilar invagination at computed tomography. Spine 2016;41(17):1365-1371

9 Kovero O, Pynnönen S, Kuurila-Svahn K, Kaitila I, Waltimo-Sirén J. Skull base abnormalities in osteogenesis imperfecta: a cephalometric evaluation of 54 patients and 108 control volunteers. J Neurosurg 2006;105(3):361-370

10 Lu X, Forte AJ, Sawh-Martinez R, et al. Normal angulation of skull base in Apert syndrome. J Craniomaxillofac Surg 2018;46(12):2042-2051

11 Sanggarnjanavanich S, Sekiya T, Nomura Y, Nakayama T, Hanada N, Nakamura Y. Cranial-base morphology in adults with skeletal Class III malocclusion. Am J Orthod Dentofacial Orthop 2014;146(1):82-91

12 Guyot L, Richard O, Adalian P, Bartoli C, Dutour O, Leonetti G. An anthropometric study of relationships between the clival angle and craniofacial measurements in adult human skulls. Surg Radiol Anat 2006;28(6):559-563

13 Karagöz F, Izgi N, Kapíjcíjoğlu Sencer S. Morphometric measurements of the cranium in patients with Chiari type I malformation and comparison with the normal population. Acta Neurochir (Wien) 2002;144(2):165-171

14 Hwang HS, Moon JG, Kim CH, Oh SM, Song JH, Jeong JH. The comparative morphometric study of the posterior cranial fossa: what is effective approaches to the treatment of Chiari malformation type 1? J Korean Neurosurg Soc 2013;54(5):405-410 